\title{
A rare endoscopic appearance of granulomatosis with polyangiitis involving the intestine: a case report
}

\author{
Sheng-Wu Pan ${ }^{1 *}$, Chang Wang ${ }^{1}$, Xin Zhang ${ }^{1}$, Li Zhang ${ }^{1}$, Qi-Qi Yan ${ }^{1}$, Cai-Juan Zhao ${ }^{1}$, Cheng Chang ${ }^{1}$ \\ and Xiao-Dong Luan ${ }^{2}$
}

\begin{abstract}
Background: The involvement of granulomatosis with polyangiitis is less frequent in the intestine.

Case presentation: We present a case of Wegener's granulomatosis with unusual endoscopic appearance, involvement in a young man's gastrointestinal tract. A 45-year-old man was diagnosed with Wegener's granulomatosis 11 years ago, and relapsed with abdominal pain and melena. A colonoscopy was performed, and the appearance of mucosal lesions with an unusual annular black membrane was observed. A black ring-shaped membranous tissue adhered to the surface of the colon wall, which could be traversed by an endoscopic forepart.

Conclusion: Biopsy of the black membrane revealed degenerative colonic mucosal tissues, while deep colonic biopsy revealed inflammatory granulation tissues. This has not been reported in previous documents.
\end{abstract}

Keywords: Granulomatosis with polyangiitis, Wegener's granulomatosis, Gastrointestinal tract bleeding, Hemorrhagic colitis, Intestinal tract

\section{Background}

Granulomatosis with polyangiitis (GPA), which is also known as Wegener's granulomatosis (WG), is a necrotizing granulomatous vasculitis with small arteriovenous and capillary involvement [1]. At present, its cause remains unknown, and it belongs to autoimmune diseases. The clinical manifestation is usually multi-system organ damage, which mainly involve the upper and lower respiratory tract, kidneys and skin. The involvement of the intestinal tract is relatively rare, although several previous articles have reported the clinical manifestations of gastrointestinal tract involvement in GPA [2-7]. However, the endoscopic imaging of intestinal lesions in GPA is relatively rare. Here we report a case of GPA involving the intestine with an unusual endoscopic appearance.

\footnotetext{
*Correspondence: pansw021763@163.com

'Department of Gastroenterology, People's Liberation Army 264 Hospital, No. 30, Qiaodong Street, Yingze District, Taiyuan 030000, Shanxi Province, China Full list of author information is available at the end of the article
}

\section{Case presentation}

A 45-year-old male was hospitalized due to bloody nasal discharge, hemoptysis and rash for 11 years, which aggravated after 2 weeks, and presented with abdominal pain and melena for 1 month. The patient was hospitalized and diagnosed with WG 11 years ago. Furthermore, he had rashes on his face, trunk, limbs and feet, and had oral ulcers, perianal ulcers, and sinusitis.

The laboratory tests revealed the following: leucocytes count of $8.5 \times 10^{9} / \mathrm{L}$, hemoglobin level of $79 \mathrm{~g} / \mathrm{L}$, urine protein $(+)$, microhematuria $(+)$, erythrocyte sedimentation rate of $50 \mathrm{~mm} / \mathrm{h}, \mathrm{c}$-ANCA (antineutrophil cytoplasmic autoantibodies) with a titre of 1 in 100 , and PR3-ANCA (anti-neutrophil cytoplasmic antibodies proteinase 3) of $>200 \mathrm{RU} / \mathrm{ml}$. Computed tomography (CT) revealed left frontal and ethmoid sinusitis, and bilateral maxillary sinusitis. Based on these clinical features and laboratory findings, the patient's diagnosis of WG was accurate. In order to clarify the cause of the abdominal pain, a colonoscopy was performed with the written informed consent of the patient. Different sizes of irregular ulcerations, which were $3-4 \mathrm{~cm}$ and $1-2 \mathrm{~cm}$ in diameter,

(c) The Author(s). 2018 Open Access This article is distributed under the terms of the Creative Commons Attribution 4.0 International License (http://creativecommons.org/licenses/by/4.0/), which permits unrestricted use, distribution, and reproduction in any medium, provided you give appropriate credit to the original author(s) and the source, provide a link to the Creative Commons license, and indicate if changes were made. The Creative Commons Public Domain Dedication waiver (http://creativecommons.org/publicdomain/zero/1.0/) applies to the data made available in this article, unless otherwise stated. 


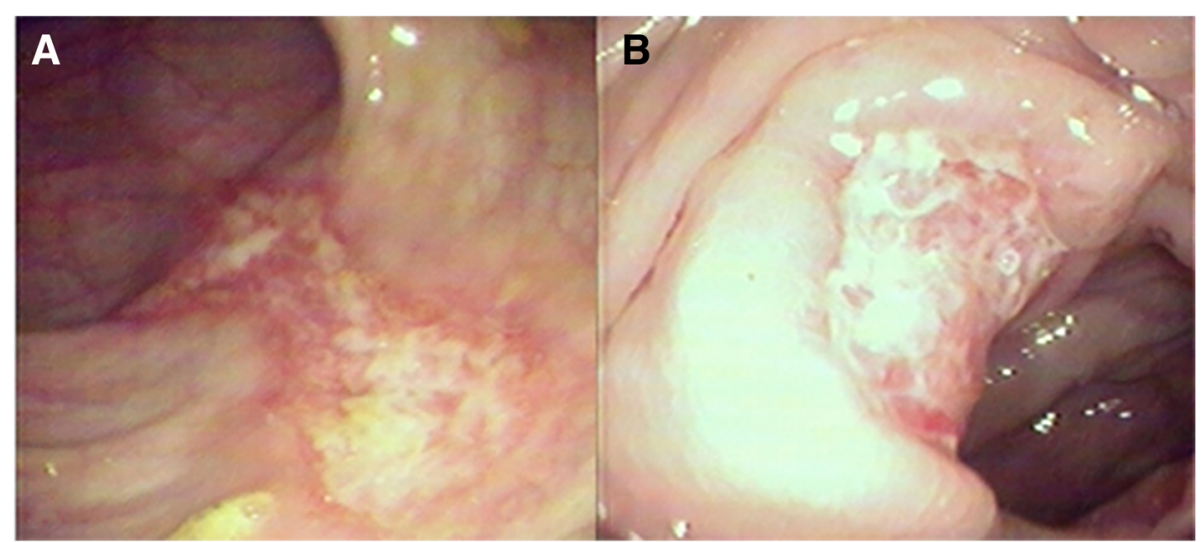

Fig. 1 a Large ulcer: the base was covered with white fibrin coating. b Rectal circular ulcer: the rolled margins are shown

were scattered at different intervals throughout the colon (Fig. 1). The larger ulcers presented raised margins and fibrin coatings on the base. Colonic biopsies revealed inflammatory granulation tissues. At approximately $40 \mathrm{~cm}$ from the anus, an annular black membrane, which was approximately $4 \mathrm{~cm}$ in diameter, adhered to the surface of the intestinal wall. The membrane could be lifted using biopsy forceps. Part of the membranous substances appeared like mucosal surface tissues, and was completely separated from the intestinal wall. The colonoscope could pass through the membrane, and erosions and ulcers were scattered at the

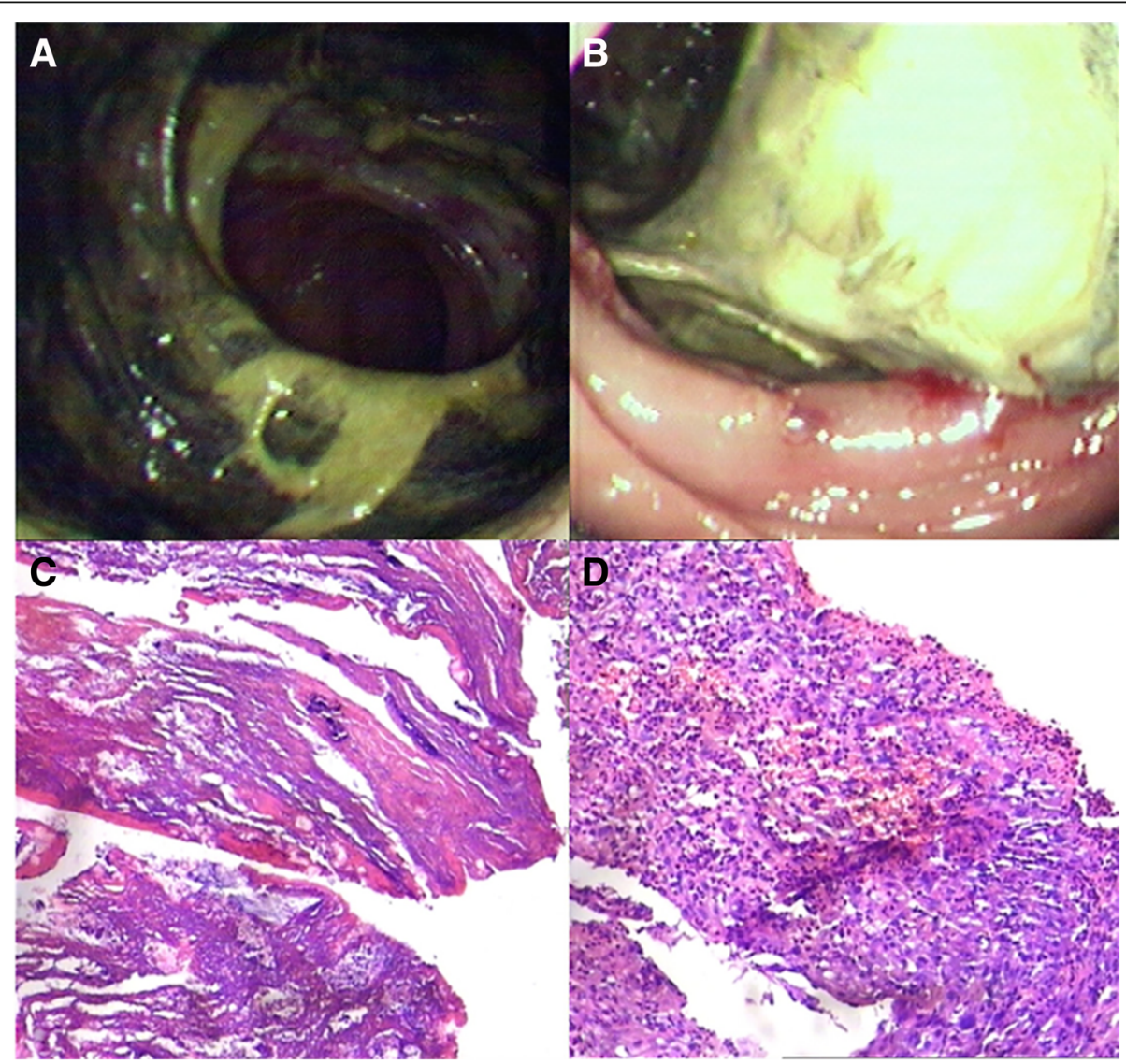

Fig. 2 a and $\mathbf{b}$ A black annular membrane, which was tunnel-like, allowing the colonoscopy to pass through. There are scattered erosions and ulcers at the bottom $(H \& E \times 20)$. c Degenerative colonic mucosal tissue: only have contours. $\mathbf{d}$ Inflammation granulation tissue: no normal colon glands $(H \& E \times 10)$ 
bottom (Fig. 2a and b). The membrane biopsy revealed degenerative colonic mucosal tissues, while the colonic biopsy revealed inflammatory granulation tissues without normal colon glands (Fig. 2c and d). Oral prednisolone $(60 \mathrm{mg} / \mathrm{d})$ combined with intravenous cyclophos phamide $(600 \mathrm{mg} / \mathrm{d}$, once) was given. The patient was rehabilitated and discharged after 10 days of treatment. Symptoms including bloody nasal discharge, hemoptysis, skin rash and abdominal pain all disappeared.

\section{Discussion and conclusions}

Granulomatous vasculitis is a necrotizing small-vessel vasculitis, and granulomatous inflammation is strongly associated with anti-neutrophil cytoplasmic autoantibodies [8]. The typical clinical manifestation is a triple syndrome, that is, upper respiratory disease, pulmonary inflammation and glomerulonephritis. Gastrointestinal tract involvement is uncommon, and is usually found at autopsy. The types of lesions mainly include submucosal edema, ulcers, hemorrhage, mesenteric ischemia, intestinal obstruction and perforation. The diagnosis of gastrointestinal complications depends largely on these clinical manifestations.

Pagnoux et al. [9] conducted a study on 62 patients with systemic necrotizing vasculitis that involved the gastrointestinal tract, and found that the most common symptoms were abdominal pain (97\%), nausea, vomiting, diarrhea, bloody stools, and melena. Furthermore, previous studies have also observed these symptoms [10,11]. The locations of GPA lesions in the gastrointestinal tract are diverse, and can involve all parts of the intestine. The most common pathological manifestations are ulcer, intestinal necrosis and perforation $[2,3,10,11]$.

Although the present understanding of gastrointestinal lesions in GPA patients has increased, there are few reports on the endoscopic appearance of GPA involving the bowel with accompanying images. In previous years, Robin et al. [12] reported a case of GPA with intestinal lesions mainly characterized by ulcers. However, the tissue biopsy was nonspecific inflammation, and lacked the characteristics of granulomatous vasculitis. Endoscopic biopsy findings are often non-specific inflammation, ulcers, or erosions, and these can rarely be diagnosed as GPA. Camilleri et al. [10] pointed out that this may be correlated to superficial tissue biopsy, because the small and medium blood vessels are located deeper under the mucosa. Therefore, it is also necessary to distinguish between infectious bowel diseases, non-infectious inflammatory bowel diseases and ischemic colitis, such as Crohn's disease characterized by aphthous ulcers, paving stone-like changes, and segmental lesions and ischemic enteritis characterized by longitudinal map-like ulcers. Besides, side effects of immunosuppressants should also be excluded. In the present case of GPA, the colonoscopy has revealed a manifestation of black ring-shaped lesion not previously reported in any disease. The degenerative intestine mucosal tissue formed a black ring-shaped membranous tissue that could be traversed by an endoscope. The intestinal wall biopsies beneath it had characteristics of inflammatory granulation, with no normal colon glands. This has not been observed in previous studies. However, colonoscopy was not performed after treatment with immunosuppressants and glucocorticoids.

In conclusion, when GPA patients suffer from abdominal pain, diarrhea, bloody stools, or melena, the differential diagnosis should be made while taking into account the possibility of granulomatous vasculitis involving the gastrointestinal tract. Colonoscopy combined with tissue biopsy can help to determine the nature of the disease, and provide an effective method for differential diagnosis.

Abbreviations
GPA: Granulomatosis with polyangiitis; WG: Wegener's granulomatosis

\section{Acknowledgements}

N/A

\section{Funding}

Not applicable

Availability of data and materials

The datasets used and/or analysed during the current study available from the corresponding author on reasonable request.

\section{Authors' contributions \\ SWP, Substantial contributions to the conception and design of the work; And 2) SWP, CW, XZ, LZ, QQY, CJZ, CC, XDL, the acquisition, analysis, and interpretation of data for the work; And 3) SWP, drafting the work; AND 4) SWP, CW, XZ, LZ, QQY, CJZ, CC, XDL, revising it critically for important intellectual content; AND 5) SWP, CW, XZ, LZ, QQY, CJZ, CC, XDL, final approval of the version to be published; AND 6) SWP, CW, XZ, LZ, QQY, CJZ, $\mathrm{CC}, \mathrm{XDL}$, agreement to be accountable for all aspects of the work in ensuring that questions related to the accuracy or integrity of any part of the work are appropriately investigated and resolved.}

Ethics approval and consent to participate

This study was conducted in accordance with the declaration of Helsinki. This study was conducted with approval from the Ethics Committee of People's Liberation Army 264 Hospital. Written informed consent was obtained from the participant.

\section{Consent for publication}

Written informed consent to publish the clinical details and images of the patient was obtained.

\section{Competing interests}

The authors declare that they have no competing interests.

\section{Publisher's Note}

Springer Nature remains neutral with regard to jurisdictional claims in published maps and institutional affiliations.

\section{Author details}

'Department of Gastroenterology, People's Liberation Army 264 Hospital, No. 30, Qiaodong Street, Yingze District, Taiyuan 030000, Shanxi Province, China. ${ }^{2}$ Public Relations Branch,Taiyuan Red Cross Blood Center, Taiyuan 030022, China. 
Received: 26 July 2018 Accepted: 14 October 2018

Published online: 25 October 2018

\section{References}

1. Zhao MH, Short AK, Lockwood CM. Antineutrophil cytoplasm autoantibodies and vasculitis. Curr Opin Hematol. 1995;2:96-102.

2. Yoshikawa A, Yoshida S, Takeuchi T, Fujiki Y, Makino S, Hanafusa T. Gastrointestinal involvement at the onset of granulomatosis with polyangiitis: a case report. Mod Rheumatol. 2017;27:162-4.

3. Masiak A, Zdrojewski Ł, Zdrojewski Z, Bułło-Piontecka B, Rutkowski B. Gastrointestinal tract involvement in granulomatosis with polyangiitis. Prz Gastroenterol. 2016;11:270-5.

4. Halawani HM, Khalife M. Gastrointestinal complication of granulomatosis with Polyangiitis. N Engl J Med. 2016;374:2159

5. Kiboshi T, Isoda K, Furukawa K, Wakahara T, Otani K, Ueda K, Konma J, Teramura K, Ueno N, Fujiwara H, Shoda T. Granulomatosis with Polyangiitis complicated with gastrointestinal perforation: a case report and review of literature. Nihon Rinsho Meneki Gakkai Kaishi. 2017;40:382-6.

6. Sinnott JD, Matthews P, Fletcher S. Case report: colitis: an unusual presentation of Wegener's granulomatosis[J]. BMJ Case Rep. 2013;2013.

7. Kitamura N, Matsukawa Y, Takei M, et al. Wegener's granulomatosis complicated with intestinal ulceration[J]. Mod Rheumatol. 2004:14(6):480-4.

8. Kallenberg CG, Heeringa P, Stegeman CA. Mechanisms of disease: pathogenesis and treatment of ANCA-associated vasculitides. Nat Clin Pract Rheumatol. 2006;2:661-70.

9. Pagnoux C, Mahr A, Cohen P, Guillevin L. Presentation and outcome, of gastrointestinal involvement in systemic necrotizing vasculitides: analysis of 62 patients with polyarteritis nodosa, microscopic Polyangiitis, Wegener granulomatosis, Churg-Strausssyndrome or rheumatoid arthritis-associated vasculitis. Medicine (Baltimore). 2005;84:115-28.

10. Camilleri M, Pusey CD, Chadwick VS, Rees AJ. Gastrointestinal manifestations of systemic vasculitis. Q J Med. 1983;52:141-9.

11. Haworth SJ, Pusey CD. Severe intestinal involvement in Wegener's granulomatosis. Gut. 1984;25:1296-300.

12. Wilson RT, Dean PJ, Upshaw JD, Wruble LD. Endoscopic appearance of Wegener's granulomatosis involving the colon. Gastrointest Endosc. 1987;33:388-9.

Ready to submit your research? Choose BMC and benefit from:

- fast, convenient online submission

- thorough peer review by experienced researchers in your field

- rapid publication on acceptance

- support for research data, including large and complex data types

- gold Open Access which fosters wider collaboration and increased citations

- maximum visibility for your research: over $100 \mathrm{M}$ website views per year

At BMC, research is always in progress.

Learn more biomedcentral.com/submissions 